\title{
Relation between malodor, ambient hydrogen sulfide, and health in a community bordering a landfill
}

\author{
Christopher D. Heaney, Ph.D. ${ }^{1}$, Steve Wing, Ph.D. ${ }^{1}$, Robert L. Campbell ${ }^{2}$, David Caldwell ${ }^{2}$, \\ Barbara Hopkins ${ }^{2}$, David Richardson ${ }^{3}$, and Karin Yeatts, Ph.D. ${ }^{1}$ \\ ${ }^{1}$ Department of Epidemiology, Gillings School of Global Public Health, University of North \\ Carolina at Chapel Hill, CB\# 7435, Chapel Hill, NC 27599-7435 USA \\ ${ }^{2}$ Rogers-Eubanks Neighborhood Association, PO Box 16901, Chapel Hill, NC, 27516-6901 USA \\ ${ }^{3}$ Institute for the Environment, University of North Carolina at Chapel Hill, CB\#1105 Chapel Hill, \\ NC 27599-1105 USA
}

\begin{abstract}
Background-Municipal solid waste landfills are sources of air pollution that may affect the health and quality of life of neighboring communities.

Objectives-To investigate health and quality of life concerns of neighbors related to landfill air pollution.

Methods-Landfill neighbors were enrolled and kept twice-daily diaries for $14 \mathrm{~d}$ about odor intensity, alteration of daily activities, mood states, and irritant and other physical symptoms between Jan-Nov, 2009. Concurrently, hydrogen sulfide $\left(\mathrm{H}_{2} \mathrm{~S}\right)$ air measurements were recorded every 15-min. Relationships between $\mathrm{H}_{2} \mathrm{~S}$, odor, and health outcomes were evaluated using conditional fixed effects regression models.
\end{abstract}

\begin{abstract}
Results-Twenty-three participants enrolled and completed 878 twice-daily diary entries. $\mathrm{H}_{2} \mathrm{~S}$ measurements were recorded over a period of $80 \mathrm{~d}$ and 1 -hr average $\mathrm{H}_{2} \mathrm{~S}=0.22 \mathrm{ppb}(\mathrm{SD}=0.27$; range: $0-2.30 \mathrm{ppb}$ ). Landfill odor increased 0.63 points (on 5-point Likert-type scale) for every 1 ppb increase in hourly average $\mathrm{H}_{2} \mathrm{~S}$ when the wind was blowing from the landfill towards the community (95\% confidence interval (CI): $0.29,0.91)$. Odor was strongly associated with reports of alteration of daily activities (odds ratio $(\mathrm{OR})=9.0 ; 95 \% \mathrm{CI}$ : 3.5, 23.5), negative mood states $(\mathrm{OR}=5.2 ; 95 \% \mathrm{CI}: 2.8,9.6)$, mucosal irritation $(\mathrm{OR}=3.7 ; 95 \% \mathrm{CI}=2.0,7.1)$ and upper respiratory symptoms $(\mathrm{OR}=3.9 ; 95 \% \mathrm{CI}: 2.2,7.0)$, but not positive mood states $(\mathrm{OR}=0.6 ; 95 \%$ CI: $0.2,1.5)$ and gastrointestinal (GI) symptoms (OR $=1.0 ; 95 \%$ CI: 0.4, 2.6).
\end{abstract}

\footnotetext{
(C) 2011 Elsevier Inc. All rights reserved.

Corresponding Author: Christopher D. Heaney, Department of Epidemiology, Gillings School of Global Public Health, University of North Carolina at Chapel Hill, CB\# 7435, Chapel Hill, NC 27599-7435 USA, Phone: (919) 966-7410, Fax: (919) 966-2089 cheaney@email.unc.edu.

Publisher's Disclaimer: This is a PDF file of an unedited manuscript that has been accepted for publication. As a service to our customers we are providing this early version of the manuscript. The manuscript will undergo copyediting, typesetting, and review of the resulting proof before it is published in its final citable form. Please note that during the production process errors may be discovered which could affect the content, and all legal disclaimers that apply to the journal pertain.

HUMAN PARTICIPANT PROTECTION

This study was approved annually by the institutional review board of the University of North Carolina at Chapel Hill. All study participants provided informed consent.

FINANCIAL INTERESTS DECLARATION

No commercial support was received for any aspect of this project and the authors declare that they have no conflicts of interest.
} 
Conclusions-Results suggest air pollutants from a regional landfill negatively impact the health and quality of life of neighbors.

\section{Keywords}

Community-driven research; solid waste landfills; air pollution; hydrogen sulfide; malodor; health

\section{INTRODUCTION}

Municipal solid waste has created public health problems ever since the emergence of cities (Louis, 2004) and, like other forms of waste, can pose a threat to environmental justice. During the last several decades, requirements for engineering controls that limit air and water pollution from municipal solid waste landfills have been adopted to protect the environment and nearby communities (EPA, 1998). In the USA, Subtitle D (EPA, 1998) landfills require liners and leachate collection systems to control surface and ground water pollution, methane capture to prevent fires and explosions, and daily cover of new waste to limit odor and attraction of insects, birds, and mammals. Landfills also create noise from heavy equipment, diesel emissions from heavy equipment and trucks, and safety problems from traffic (Taylor, 1999).

Although newer landfills may be better designed and operated than older facilities, communities near some Subtitle D landfills continue to report problems with noise, malodor, and animal pests. In the USA (Martuzzi et al., 2010) and North Carolina (Norton et al., 2007), landfills tend to be disproportionately located in areas with lower housing value and larger concentrations of people of color. Poorer housing, lack of air conditioning and clothes driers, and dependence on the local neighborhood for recreation, make low income communities more vulnerable to impacts of pollutants than communities with well-insulated homes where residents have the means to travel to other locations for exercise and entertainment at times when their homes and neighborhoods are affected by malodor.

Since 1972, the historically African-American Rogers-Eubanks community in Orange Co., North Carolina, has hosted a number of waste facilities including, most recently, a Subtitle D municipal solid waste landfill. For several decades community members have been concerned about impacts of these waste facilities on their health and quality of life. The purposes of this study, conducted in the Rogers-Eubanks community, are to measure levels of hydrogen sulfide $\left(\mathrm{H}_{2} \mathrm{~S}\right)$, a gas generated by anaerobic decomposition of organic wastes in landfills (ATSDR, 2010), track the occurrence of odors reported by community members, and evaluate relationships between $\mathrm{H}_{2} \mathrm{~S}$ exposure, reports of malodor, alterations of daily activities, mood states, and physical symptoms.

\section{MATERIALS AND METHODS}

\section{Setting and Data Collection}

This research originated from community concerns about health and quality of life in neighborhoods bordering a regional landfill in Orange Co., $\mathrm{NC}$ and was linked to community education and organizing efforts for environmental justice (Wing et al., 2008b). The Rogers-Eubanks Neighborhood Association, a 501(c)(3) community-based organization representing predominantly African-American neighborhoods bordering the regional landfill, brought these concerns to the attention of researchers at the Department of Epidemiology at the University of North Carolina at Chapel Hill. Research questions were developed in partnership with the Rogers-Eubanks Neighborhood Association, and the study followed principles of community-based participatory research (Israel et al., 2005; Minkler et al., 2006; O'Fallon and Dearry, 2002) and community-driven research (Heaney et al., 
2007). Individuals were eligible to participate if they lived within 0.75 miles of the Orange Co., NC regional landfill and were at least 18 years old. Volunteers recruited by three of us (RLC, DC, BH) participated in the study in rounds of two to eleven members based on the proximity of their homes and availability to collect data during the two-week period. Volunteers were eligible to participate in up to two rounds of data collection. Prior to beginning data collection participants attended a structured training session at which they provided informed consent and practiced data collection activities. Twice daily for 14 days, participants spent 5 minutes outside their homes and then returned indoors to rate landfill odor, usually in the morning and evening; these twice-daily times were chosen at the training session and maintained throughout data collection as closely as possible. Participants rated odor on a 5-point Likert-type scale from 0 (none) to 4 (very strong). They also provided descriptions of the odor. Following the odor rating, participants responded to questions about alteration of daily activities in the previous 12-hr because of landfill odor, 7 mood states, and irritant and physical symptoms. Questions on mood states were also rated on a 5-point Likert-type scale from 0 (not at all) to 4 (severe) and included: "How do you feel now: (a) stressed?, (b) nervous or anxious?, (c) gloomy, blue or unhappy?, (d) angry, grouchy or bad-tempered?, (e) confused or unable to concentrate, (f) active, energetic, or full of pep?, (g) weary, bushed, or exhausted?" The "stressed?" question was an ad-hoc singleitem measure (Cohen et al., 1997; Littman et al., 2006), and the remaining 6 questions came from the Profile of Mood States instrument (McNair et al., 1971; Schiffman et al., 1995). Questions on acute irritant and physical symptoms included: "Do you currently have any of the following symptoms?" and covered a range of categories including mucous membrane irritation ("burning, tearing, or irritated eyes", "burning or irritated nose", "burning or scratchy throat"), upper respiratory ("excessive cough", "runny nose or congestion", "sore throat", "difficulty breathing"), gastrointestinal (GI) ("loss of appetite", "nausea or vomiting", "diarrhea"), skin irritation ("skin irritation or redness", "ulcer or boils on skin", "round patches or scaly areas on skin", "white or moist areas on skin", "rash with spots or bumps", "itching"), "headache", "general ill feeling", "fever or chills", "light headed or dizzy", "trouble urinating" and "ringing in ears". Participants rated irritant and physical symptoms on a 4-point Likert-type scale from 0 (none) to 3 (severe).

In this study, $\mathrm{H}_{2} \mathrm{~S}$ measurements are used as a marker of a complex mixture of odorant chemicals produced by landfills. During the study period from January to November, 2009, we placed $\mathrm{H}_{2} \mathrm{~S}$ monitors along the northern boundary of the Rogers-Eubanks community near the landfill. Monitors were deployed several days before the start of each round of diary data collection. The location was chosen to be free from trees or structures that could affect air flow between the landfill and the community, which is south of the landfill. From January 9 - February 25, 2009, an MDA Scientific Single Point Monitor (Honeywell Analytics, Inc., North America, Linconlnshire, IL) provided concentrations of $\mathrm{H}_{2} \mathrm{~S}$ (parts per billion - ppb) averaged over 15-min intervals. From September 25 - November 22, 2009, a Thermo Scientific 450C pulsed fluorescence $\mathrm{H}_{2} \mathrm{~S}-\mathrm{SO}_{2}$ analyzer (Thermo) (Thermo Fisher Scientific, Waltham, MA) provided concentrations of $\mathrm{H}_{2} \mathrm{~S}(\mathrm{ppb})$ every 5 minutes. The $\mathrm{H}_{2} \mathrm{~S}$ detection limit for the single point monitor and Thermo instruments is $1 \mathrm{ppb}$ and $0.5 \mathrm{ppb}$, respectively (NRC, 2003). Hourly measurements of wind direction from an observation station $0.5 \mathrm{mi}$ from the landfill and community were obtained from the North Carolina state climate office's Climate Retrieval and Observations Network of the Southeast database (CRONOS, 2010). Diary records were linked in time to $\mathrm{H}_{2} \mathrm{~S}$ and wind direction variables and 1-hr mean $\mathrm{H}_{2} \mathrm{~S}$ concentrations were calculated using 2.5 minutes before the end-time of each diary record as the mid-point of the 1-hr mean. 


\section{Statistical Analysis}

We analyzed twice-daily odor ratings, which were recorded by participants at their homes at roughly the same time of day, in relation to $\mathrm{H}_{2} \mathrm{~S}$. We analyzed twice daily reports of landfill odor during the previous 12-hr in relation to reports of alteration of daily activities because of landfill odor in the previous 12-hr. Finally, we examined the association between twicedaily ratings of landfill odor and reports of mood states and irritant and other physical symptoms. Relationships between 1-hr average $\mathrm{H}_{2} \mathrm{~S}$ concentration and twice-daily odor ratings were evaluated by conditional fixed effects linear regression models (Allison, 2005). Since the goal of this analysis is to make inferences about within-person variation of transient explanatory variables while controlling for stable characteristics of individuals (both measured and unmeasured), conditional fixed effects models are more appropriate than mixed models or generalized estimating equations (Allison, 2005). Conditional fixed effects models evaluate within-individual effects by differencing across repeated measures within each person and then averaging those differences across all persons in the study, rather than by making assumptions about the distribution of individual effects (Allison, 2005). In this design, conditional fixed effects models estimate exposure-outcome relationships by treating each individual as his or her own control. We fit an interaction term between $\mathrm{H}_{2} \mathrm{~S}$ and wind direction to assess potential modification of the $\mathrm{H}_{2} \mathrm{~S}$-odor relationship by wind direction - during periods when the wind was blowing towards the community (northerly) compared to time periods when the wind was blowing away from the community (non-northerly). We assessed the relation of average odor ratings during the previous 12-hr (on a scale from none (0) to very strong (4)) with reports of alteration of daily activities in the previous $12-\mathrm{hr}$ and the relation of participants' twice-daily odor ratings with mood states and irritant and physical symptoms by conditional fixed effects logistic regression (Allison, 2005). In these logistic models, symptoms were defined as absent vs. present (i.e., 0 vs. $\geq 1$ ), and the number of informative observations is dependent upon individuals showing variability in both exposure and outcome. Conditional fixed-effects regression models were adjusted for morning and evening diary record time periods because time-of-day could act as a confounder due to its potential to be related to both air pollutants and health outcomes. We report $95 \%$ confidence intervals even though they are often misinterpreted in non-randomized studies as reflecting the probability that the true value of the effect lies within the interval. Results were also compared with mixed models using SAS PROC MIXED with an AR(1) covariance structure, generalized estimating equation models in PROC GENMOD with an AR(1) covariance structure, and SAS PROC NLMIXED with random intercepts. All analyses were completed using SAS version 9 (SAS Institute Inc., Cary, NC).

\section{RESULTS}

During 5 rounds of data collection, 23 volunteers participated, including 12 men and 11 women, 22 who self-identified as Black, and 14 who reported that they had grown up near a landfill (Table 1). These participants completed 878 twice-daily diary records (8 people participated in two rounds of data collection). The 15 -min average $\mathrm{H}_{2} \mathrm{~S}$ concentration was $0.28 \mathrm{ppb}(\mathrm{SD}=0.52$; range $=0-14.86 \mathrm{ppb})$. The $1-\mathrm{hr}$ mean $\mathrm{H}_{2} \mathrm{~S}$ concentration during diary data collection was $0.22 \mathrm{ppb}(\mathrm{SD}=0.27$; range $=0-2.30 \mathrm{ppb})$. Ambient $\mathrm{H}_{2} \mathrm{~S}$ was above the detection limit during $586(72 \%)$ diary time periods and landfill odor was reported during $213(26 \%)$ diary recording time periods (Table 2). Participants reported a range of odor intensity, from faint (13\%), moderate (5\%), strong (7\%), to very strong (1\%) (Table 2).

\section{Relationship Between Hydrogen Sulfide $\left(\mathrm{H}_{2} \mathrm{~S}\right)$ and Landfill Odor}

Figure 1 compares the distributions of odor ratings during times when 1-hr average $\mathrm{H}_{2} \mathrm{~S}$ was below versus above the detection threshold. Although the distribution of odor ratings is 
shifted downwards when $\mathrm{H}_{2} \mathrm{~S}$ was below threshold, the strongest odor reports (ratings of 3 and 4) were more common when $\mathrm{H}_{2} \mathrm{~S}$ was below threshold. Landfill odor increased 0.30 points (on a 5-point Likert-type scale) for every $1 \mathrm{ppb}$ increase in hourly average $\mathrm{H}_{2} \mathrm{~S}(95 \%$ confidence interval (CI): $0.09,0.52$ )) (Table 3 ). The magnitude of the $\mathrm{H}_{2} \mathrm{~S}$-odor relationship was greater during times when the wind was blowing in a Northerly direction towards the community (beta $=0.63 ; 95 \%$ CI: $0.29,0.91$ ) (Table 3 ) compared to times when the wind was blowing in a non-Northerly direction away from the community (beta $=0.08 ; 95 \% \mathrm{CI}$ : $-0.18,0.36$ ) (Table 3). Estimates of the $\mathrm{H}_{2} \mathrm{~S}$-odor association using the $\mathrm{AR}(1)$ covariance structure and random intercepts were similar to results of conditional fixed effects linear models (data not shown).

\section{Relationship Between Landfill Odor and Alteration of Daily Activities}

A strong positive relationship was observed between reports of landfill odor in the 12-hr before each twice-daily diary record and reports of alteration of daily activities in the previous $12-\mathrm{hr}$. The odds of reporting any alteration of daily activities when there was odor in the previous $12-\mathrm{hr}$ was 9.0 (95\% CI: 3.5, 23.5) times the odds of reporting any alteration of daily activities in the previous 12-hr when there was no odor in the previous 12-hr ) (Table 4). The average odor rating during the 12 -hr before each outdoor diary recording period was positively associated with reports of doing things differently or with difficulty during the previous $12-\mathrm{hr}(\mathrm{OR}=3.3 ; 95 \% \mathrm{CI}$ : 1.9, 5.6) (Table 4) and deciding not to do things because of landfill odor during the previous $12-\mathrm{hr}(\mathrm{OR}=2.9 ; 95 \% \mathrm{CI}: 1.7,4.7$; Table 5) (Table 4). Estimates of this association using the AR(1) covariance structure and random intercepts were similar to results of conditional fixed effects logistic models (data not shown).

\section{Relationship Between Landfill Odor and Mood States, Irritant, and Physical Symptoms}

Reports of landfill odor during twice-daily periods of sitting outside were positively associated with mood states and acute irritant and other physical symptoms (Tables 5 and 6). The magnitude of associations between twice-daily odor reports and acute outcomes (from strongest, to weakest) was: any negative mood states ( $\mathrm{OR}=5.2 ; 95 \% \mathrm{CI}: 2.8,9.6)$, any upper respiratory symptoms $(\mathrm{OR}=3.9 ; 95 \% \mathrm{CI}: 2.2,7.0)$, and any mucous membrane irritation (OR $=3.7 ; 95 \% \mathrm{CI}: 2.0,7.1$ ) (Table 6$)$. Strong positive associations were also observed between twice-daily odor reports and feeling "dizzy or lightheaded" ( $O R=4.1$; 95\% CI: 1.3, 12.5), "headache" (OR = 3.3; 95\% CI: 1.5, 7.4), and a "general ill feeling" (OR $=2.7 ; 95 \%$ CI: 1.6, 6.6) (Table 5). We observed little evidence that twice-daily odor reports were related to feeling "active, energetic, or full of pep" (OR = 0.6; 95\% CI: 0.2, 1.5) (Table 5), skin symptoms (e.g., skin rash, $\mathrm{OR}=1.2 ; 95 \% \mathrm{CI}$ : 0.2, 6.3) (Tables 5), ringing in the ears $(\mathrm{OR}=2.9 ; 95 \%$ CI: $0.6,14.2)$ and reports of any gastrointestinal symptoms $(\mathrm{OR}=1.0$; $95 \%$ CI: 0.4, 2.6) (Table 6). Estimates of the odor-symptom association using the AR(1) covariance structure and random intercepts were similar to results of conditional fixed effects logistic models (data not shown). Relationships of $\mathrm{H}_{2} \mathrm{~S}$ levels with mood, daily activities, and physical symptoms tended to be positive but were highly imprecise (data not shown), and some models did not converge.

\section{DISCUSSION}

Landfills are unequally distributed by race and class (Martuzzi et al., 2010; Norton et al., 2007) and produce a complex mixture of odorant and irritant air pollutants (Muezzinoglu, 2003; Sadowska-Rociek et al., 2009) that may interfere with activities of daily living, negatively impact mood states, and trigger acute irritant physical symptoms among neighbors of these facilities. Results of this study showed a positive association between ambient $\mathrm{H}_{2} \mathrm{~S}$ concentrations and neighbors' ratings of landfill malodor when the wind was 
blowing in the direction of the community. Additionally, reports of landfill odor were associated with negative ratings of health and quality of life.

Although ambient $\mathrm{H}_{2} \mathrm{~S}$ concentrations were associated with reports of landfill odor, even the highest hourly average $\mathrm{H}_{2} \mathrm{~S}$ concentrations were at or below the odor detection threshold, approximately 0.5-8 ppb (ATSDR, 2010; NRC, 2003; Powers, 2010; Saral et al., 2009). $\mathrm{H}_{2} \mathrm{~S}$ is emitted from landfills in low quantities compared to several other gases, and in this study serves as a marker of a complex mixture that is dominated by other odorant compounds. This observation is underscored by the fact that the strongest odor levels (3-4) were reported about $9 \%$ of the time when $\mathrm{H}_{2} \mathrm{~S}$ was not detectable versus only about $7 \%$ of the time when $\mathrm{H}_{2} \mathrm{~S}$ concentrations were above the detection threshold of the single point monitor and Thermo (Fig 1). Participants' qualitative descriptions of landfill odor, included rotting (garbage, food, carcasses), smoke (burning gasses), and chemical fumes, suggests that the strongest odors came from fresh garbage added to the surface of the landfill, rather than from the rotten-egg smell of $\mathrm{H}_{2} \mathrm{~S}$, which comes from anaerobic decay of buried organic material. These qualitative descriptions of landfill odor also may reflect variability in how individuals perceive odorant chemicals.

The results of our study suggest that neighbors of a regional landfill experience malodor frequently. Participants reported malodor during 213 of 816 odor ratings periods. We also observed that $\mathrm{H}_{2} \mathrm{~S}$ was positively associated with reports of malodor. The $\mathrm{H}_{2} \mathrm{~S}$-odor association was primarily observed during periods when the wind direction was blowing from the landfill towards the study community. Participants' average ratings of landfill malodor 12-hr prior to diary data collection periods were strongly associated with reports of alteration of daily activities in the previous $12-\mathrm{hr}$. We also observed a strong positive association of odor ratings during the twice-daily 5-min period of sitting outdoors with negative mood states, mucosal irritation, upper respiratory symptoms, headache, and feeling dizzy or lightheaded. Landfill malodor was not associated with reports of reports of positive mood states (feeling "active, energetic, peppy"), a composite of any gastrointestinal symptoms, or reports of skin irritation.

Potential for reporting bias is a limitation of analyses in which both the independent and dependent variables are based on the diary. Of particular concern is that people could overreport negative outcomes when they notice landfill odor (e.g., there could be correlated errors). This could occur if malodor increases negative mood states such as anger or annoyance, and if such moods lead to greater sensitivity to, or tendency to report, negative moods and physical symptoms. Although we believe participants understood the importance of accurate reporting and made an effort to provide consistent ratings, such a process could occur unconsciously, and would lead to an overestimate of the relationship between landfill odor and self-reported outcomes. If such a bias did occur, however, it was clearly not so large as to result in a generalized over-reporting of symptoms during odor episodes, because some types of symptoms showed no relationship with odor (e.g., some skin symptoms, "ringing in the ears", and any gastrointestinal symptoms (Table 5; Table 6)). Furthermore, analyses in which $\mathrm{H}_{2} \mathrm{~S}$ is the independent variable should not be subject to this potential source of bias. Inclusion of objective measures of health outcomes in future studies would reduce potential for reporting bias.

Although respiratory symptoms ( 291 of 820 diary records) and negative mood states ( 275 of 815 diary records) were reported most frequently by study participants, the strongest associations were observed between odor reports during the 12-hr before each twice daily data collection time period and alteration of daily activities in the previous 12-hr (42 of 819 diary records). There was some evidence of a positive association between 12-hr average $\mathrm{H}_{2} \mathrm{~S}$ (defined as a binary presence versus absence variable) and reports of having to do 
things differently in the previous 12 -hr period because of landfill odor. For example, the odds of reporting having to do things differently in the previous 12-hr when $\mathrm{H}_{2} \mathrm{~S}$ was present was 2.5 times the odds of reporting having to do things differently in the previous 12-hr when $\mathrm{H}_{2} \mathrm{~S}$ was absent $(95 \%$ CI: $0.8,7.9)$. Relationships between measures of other acute changes in health and well-being as a function of varying concentrations of $\mathrm{H}_{2} \mathrm{~S}$ were more imprecise and in some instances exhibited a lack of model convergence in conditional fixedeffects logistic regression models with $\mathrm{H}_{2} \mathrm{~S}$ included as a main effect independent (predictor) variable (data not shown).

Future studies of landfill odor and health and quality of life among neighbors may be able to improve evaluation of health outcomes as a function of objective environmental measures of airborne landfill emissions by examining $\mathrm{H}_{2} \mathrm{~S}$ as well as other air pollutants (non-methane organic compounds, mercaptans, ammonia, PM) (ATSDR, 2010; Kim, 2006) at multiple locations during diary data collection, for longer time periods, focusing on landfills with higher emissions of odorant gases, and including objective measures of health outcomes (e.g., lung function, stress biomarkers) to reduce potential for reporting bias. Although we attempted to stagger participants' 14 day enrollment periods evenly during the 80 days of data collection between Jan.-Nov. 2009, it was not possible to initiate enrollments during the summer months (June-August, 2009). Future studies should include data collection during summer months to better capture seasonal variation of odorant air pollutants from landfills.

Numerous studies in areas near landfills in Europe have relied on odor ratings as a preferred method of characterizing odor (Aatamila et al., 2010; Capelli et al., 2008; Drew et al., 2007; Heroux et al., 2004; Nicolas et al., 2006; Van Langenhove and Van Broeck, 2001), supporting an understanding that reported odor could be a better measure of the complex mixture of air pollutants from landfills than $\mathrm{H}_{2} \mathrm{~S}$ measurements at a single location within a community. Belgian researchers developed an estimation of odor emission rates from landfills using the sniffing team method whereby teams of field observers follow odor rating protocols to delineate regions in which odor impact is experienced (Nicolas et al., 2006). We expect that participants' ratings of odor at roughly the same time twice each day at the same location outside their homes would provide more accurate classification of odor exposure than measurement of $\mathrm{H}_{2} \mathrm{~S}$ at a single location within the community.

In this study, the aim was to make valid within-participant comparisons to determine if increases in ambient $\mathrm{H}_{2} \mathrm{~S}$ concentrations or odor ratings were associated with alterations of daily activities, mood states, and physical symptoms. The strengths of this study include use of an analytic method which achieves complete control of potential confounding from timeinvariant measured or unmeasured characteristics of individuals, concurrent measurement of $\mathrm{H}_{2} \mathrm{~S}$ and acute changes in health and quality of life, and community participation in research that is tied to community efforts to address environmental injustice related to landfills. Weaknesses of the study include the small sample size, generalizability, lack of measurements during the summer months, lack of measurements of landfill air pollutants other than $\mathrm{H}_{2} \mathrm{~S}$, and a lack of clinical measures of symptoms.

\section{CONCLUSIONS}

To the best of our knowledge, this is one of the first studies to measure ambient concentrations of malodorous gaseous emissions from a landfill concurrently with neighbors' reports of acute changes in odor and states of health and well-being. Our study demonstrates a positive association of low-level $\mathrm{H}_{2} \mathrm{~S}$ exposure from a landfill with reports of malodor when the wind was blowing from the landfill towards the community. Malodor has been shown to negatively impact the health and well-being of populations neighboring confined animal facilities, wastewater treatment plants, and biosolids recycling operations 
(Avery et al., 2004; Horton et al., 2009; Schiffman et al., 2004; Schiffman and Williams, 2005; Schinasi et al., 2011; Shusterman, 1992a; Shusterman, 1992b; Wing et al., 2008a). Our findings support research suggesting that $\mathrm{H}_{2} \mathrm{~S}$ and other malodorous gases can trigger irritant and physical symptoms (Schiffman and Williams, 2005; Shusterman, 1992b). With an understanding of health as, "a state of complete physical, mental, and social well-being and not merely the absence of disease or infirmity" (WHO, 1948), our results provide evidence of impacts of landfill malodor on health and health-related quality of life in a disproportionately African-American community bordering the Orange Co., NC regional landfill. Concerns about these impacts have been raised by landfill neighbors in Orange Co., NC since 1972 when a regional landfill was sited in the community. In NC, solid waste facilities are disproportionately located in communities of color and of low-wealth (Norton et al., 2007). Martuzzi et al., (2010), observed similar patterns across the US and Europe (Martuzzi et al., 2010). With 3,581 active municipal landfills in the US, according to US Environmental Protection Agency estimates (EPA, 1996), malodor and ambient air pollutant concentrations should be considered in future studies of health impacts of environmental injustice in communities bordering landfills.

\section{Research Highlights}

- We investigate health and quality of life concerns of landfill neighbors related to air pollution.

- We evaluate relationships between ambient hydrogen sulfide, odor, and health.

- Landfill odor increased when hydrogen sulfide increased when the wind was blowing towards the community.

- Landfill odor was positively related to altered activities and mood and physical symptoms.

- Results suggest landfill air pollutants negatively impact neighbors' health and quality of life.

\section{ABBREVIATIONS}

CI confidence interval

$\mathbf{H}_{2} \mathbf{S} \quad$ hydrogen sulfide

OR odds ratio

PM particulate matter

\section{Acknowledgments}

Funding for this work was provided by the UNC Program on Ethnicity, Culture, and Health Outcomes and the National Institutes of Health Clinical and Translational Science Awards from the NC Translational and Clinical Sciences Institute (UL1RR025747 from the National Center for Research Resources). Dr. Heaney received support through the National Institute of Environmental Health Sciences environmental epidemiology training grant (T32 ES007018) at the UNC Department of Biostatistics and at the time of this study was a W.K. Kellogg Foundation Health Scholar-Community Track at the University of North Carolina Center for Health Promotion and Disease Prevention and Health Behavior and Health Education Department. We thank Bishop Ila McMillan and the congregation members of the Faith Tabernacle Oasis of Love International Church for hosting community meetings and its support of the Rogers-Eubanks Neighborhood Association. This study was initiated under funding by NIEHS grant R25ES008206 as part of a graduate-level environmental justice class that included data collection by students in the class who worked with Rogers-Eubanks Neighborhood Association members. 


\section{REFERENCES}

Aatamila M, et al. Odor Annoyance near Waste Treatment Centers: A Population-Based Study in Finland. Journal of the Air \& Waste Management Association. 2010; 60:412-418. [PubMed: 20437776]

Allison, PD. Fixed effects regression methods for longitudinal data using SAS®. Cary, NC: SAS Institute Inc; 2005.

ATSDR. Agency for Toxic Substances and Disease Registry. Vol. Vol. 2010. Atlanta: 2010. Landfill gas primer: an overview for environmental health professionals.

Avery RC, et al. Odor from industrial hog farming operations and mucosal immune function in neighbors. Arch Environ Health. 2004; 59:101-108. [PubMed: 16075904]

Capelli L, et al. A comparative and critical evaluation of odour assessment methods on a landfill site. Atmospheric Environment. 2008; 42:7050-7058.

Cohen, S., et al. Strategies for measuring stress in studies of psychiatric and physical disorders. In: Cohen, S., et al., editors. Measuring Stress: A Guide for Health and Social Scientists. New York, NY: Oxford University Press; 1997.

CRONOS. North Carolina Climate Retrieval and Observations Network of the Southeast database. State Climate Office of North Carolina. 2010

Drew GH, et al. Appropriateness of selecting different averaging times for modelling chronic and acute exposure to environmental odours. Atmospheric Environment. 2007; 41:2870-2880.

EPA. Solid Waste Emergency Response. United States Environmental Protection Agency; 1996. List of municipal solild waste landfills in the United States and protectorates.

EPA. Resource Conservation and Recovery Act (RCRA) Subtitle D Regulated Facilities: State Permit Program Determination of Adequacy, State Implementation Rule. 40 CFR Parts 298, 257, and 258. United States Environmental Protection Agency, Federal Register; 1998.

Heaney CD, et al. The West End Revitalization Association's community-owned and managed research model: Development, implementation, and action. Progress in Community Health Partnerships: Research, Education, and Action. 2007; 1:339-349.

Heroux M, et al. Evaluating odour impacts from a landfilling and composting site: involving citizens in the monitoring. Water Science and Technology. 2004; 50:131-137. [PubMed: 15484753]

Horton RA, et al. Malodor as a trigger of stress and negative mood in neighbors of industrial hog operations. Am J Public Health. 2009; 99 Suppl 3:S610-S615. [PubMed: 19890165]

Israel, BA., et al. Methods in community-based participatory research for health. San Francisco: Jossey-Bass; 2005.

Kim KH. Emissions of reduced sulfur compounds (RSC) as a landfill gas (LFG): A comparative study of young and old landfill facilities. Atmospheric Environment. 2006; 40:6567-6578.

Littman AJ, et al. Reliability and validity of 2 single-item measures of psychosocial stress. Epidemiology. 2006; 17:398-403. [PubMed: 16641618]

Louis GE. A historical context of municipal solid waste management in the United States. Waste Manag Res. 2004; 22:306-322. [PubMed: 15462338]

Martuzzi M, et al. Inequalities, inequities, environmental justice in waste management and health. Eur J Public Health. 2010; 20:21-26. [PubMed: 20061348]

McNair, D., et al. Profile of Mood States. San Diego, CA: Educational and Industrial Testing Service; 1971.

Minkler M, et al. Promoting environmental justice through community-based participatory research: The role of community and partnership capacity. Health Educ Behav. 2006

Muezzinoglu A. A study of volatile organic sulfur emissions causing urban odors. Chemosphere. 2003; 51:245-252. [PubMed: 12604076]

Nicolas J, et al. Estimation of odor emission rate from landfill areas using the sniffing team method. Waste Management. 2006; 26:1259-1269. [PubMed: 16360313]

Norton JM, et al. Race, wealth, and solid waste facilities in North Carolina. Environ Health Perspect. 2007; 115:1344-1350. [PubMed: 17805426] 
NRC. Measuring emissions. In: Council, NR., editor. Air emissions from animal feeding operations: Current knowledge, future needs. Washington DC: National Academies Press; 2003.

O'Fallon LR, Dearry A. Community-based participatory research as a tool to advance environmental health sciences. Environ Health Perspect. 2002; 110 Suppl 2:155-159. [PubMed: 11929724]

Powers, W. Iowa State University Cooperative Extension Service Department of Animal Science. Vol. Vol. 2010. Ames, IA: 2010. The Science of Smell Part 1: Odor Perception and Physiological Response.

Sadowska-Rociek A, et al. Analysis of odorous compounds at municipal landfill sites. Waste Manag Res. 2009; 27:966-975. [PubMed: 19710115]

Saral A, et al. Assessment of odorous VOCs released from a main MSW landfill site in IstanbulTurkey via a modelling approach. Journal of Hazardous Materials. 2009; 168:338-345. [PubMed: 19285797]

Schiffman SS, et al. The effect of environmental odors emanating from commercial swine operations on the mood of nearby residents. Brain Res Bull. 1995; 37:369-375. [PubMed: 7620910]

Schiffman SS, et al. Potential health effects of odor from animal operations, wastewater treatment, and recycling of byproducts. J Agromedicine. 2004; 9:397-403. [PubMed: 19785232]

Schiffman SS, Williams CM. Science of odor as a potential health issue. J Environ Qual. 2005; 34:129-138. [PubMed: 15647542]

Schinasi L, et al. Air pollution, lung function, and physical symptoms in communities near concentrated Swine feeding operations. Epidemiology. 2011; 22:208-215. [PubMed: 21228696]

Shusterman D. Critical review: the health significance of environmental odor pollution. Arch Environ Health. 1992a; 47:76-87. [PubMed: 1540008]

Shusterman D. Environmental odor pollution. Arch Environ Health. 1992b; 47:388-390. [PubMed: 1444603]

Taylor D. Talking trash: the economic and environmental issues of landfills. Environ Health Perspect. 1999; 107:A404-A449. [PubMed: 10417373]

Van Langenhove H, Van Broeck G. Applicability of sniffing team observations: experience of field measurements. Water Science and Technology. 2001; 44:65-70. [PubMed: 11762485]

WHO. International Health Conference. New York, NY: World Health Organization; 1948. Preamble to the Constitution of the World Health Organization.

Wing S, et al. Air pollution and odor in communities near industrial swine operations. Environ Health Perspect. 2008a; 116:1362-1368. [PubMed: 18941579]

Wing S, et al. Integrating epidemiology, education, and organizing for environmental justice: community health effects of industrial hog operations. Am J Public Health. 2008b; 98:1390-1397. [PubMed: 18556620] 


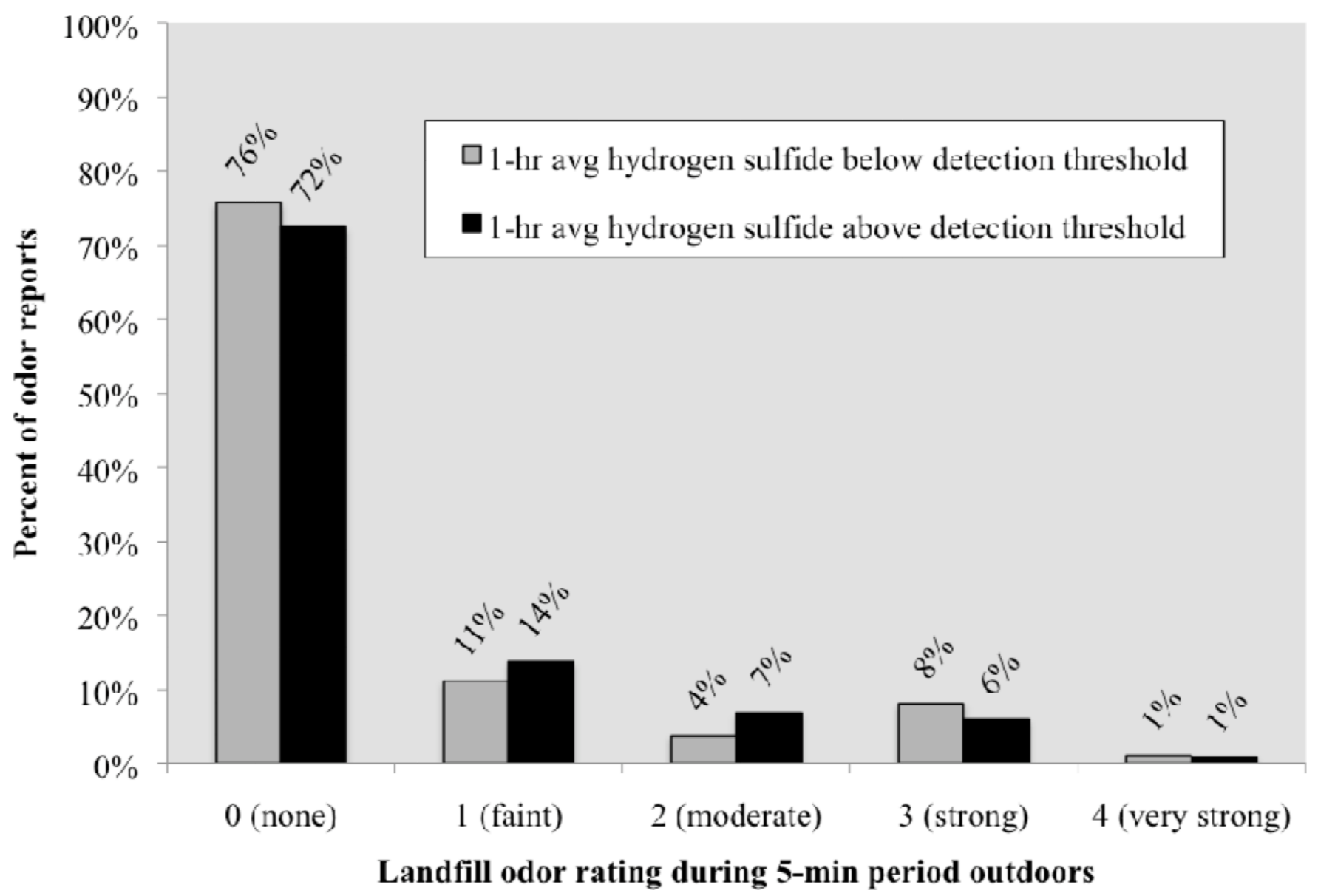

Figure 1.

Distribution of odor ratings by study participants during times when 1-hr average $\mathrm{H}_{2} \mathrm{~S}$ was below versus above the detection threshold. 
Table 1

Participant demographic characteristics.

\begin{tabular}{lc}
\hline & No. $(\%)$ \\
\hline Age & $4(17)$ \\
$18-29$ & $0(0)$ \\
$30-39$ & $3(13)$ \\
$40-49$ & $9(39)$ \\
$50-59$ & $5(22)$ \\
$60-69$ & $2(9)$ \\
$\geq 70$ & \\
Race/Ethnicity & $22(96)$ \\
Black & $1(4)$ \\
White & \\
Sex & $11(48)$ \\
Female & $12(52)$ \\
Male & \\
Grew up near landfill & \\
Yes & $14(61)$ \\
No & $6(26)$ \\
Missing & $3(13)$ \\
\hline
\end{tabular}




\section{Table 2}

Intensity of participants' twice-daily reports of odor while sitting outside.

\begin{tabular}{lc}
\hline & $\mathbf{N}(\boldsymbol{\%})$ \\
\hline Total no. of diary records & $878(100)$ \\
Total no of odor ratings & $818(93)$ \\
None & $605(74)$ \\
Faint & $103(13)$ \\
Moderate & $45(5)$ \\
Strong & $57(7)$ \\
Very strong & $8(1)$ \\
\hline
\end{tabular}




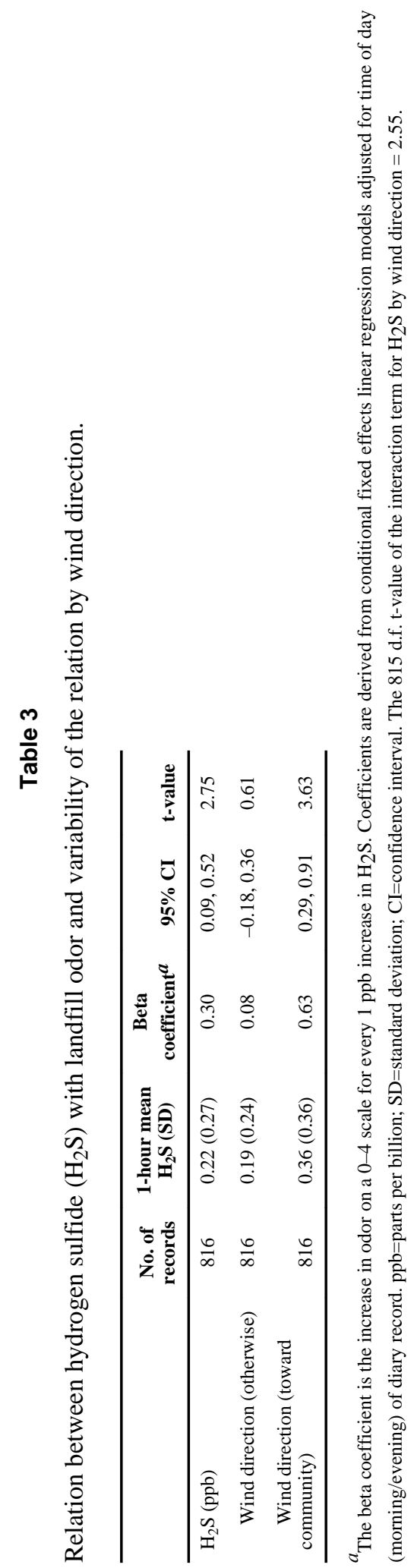


Table 4

Relation between odor reports during previous $12-\mathrm{hr}$ and alteration of daily activities in previous $12-\mathrm{hr}$.

\begin{tabular}{lccc}
\hline & $\begin{array}{c}\text { No. of } \\
\text { records }\end{array}$ & $\begin{array}{c}\text { Any odor in } \\
\text { previous 12-hr } \\
\left.\mathbf{O R}^{\boldsymbol{a}} \mathbf{( 9 5 \%} \mathbf{C I}\right)\end{array}$ & $\begin{array}{c}\text { Avg odor in } \\
\text { previous 12-hr } \\
\mathbf{O R}^{\boldsymbol{a}}(\mathbf{9 5 \%} \mathbf{C I})\end{array}$ \\
\hline $\begin{array}{l}\text { Did things differently because } \\
\text { of landfill odor }\end{array}$ & 214 & $7.4(2.9,18.8)$ & $3.3(1.9,5.6)$ \\
$\begin{array}{l}\text { Had to change daily activities } \\
\text { because of landfill odor }\end{array}$ & 160 & $8.4(3.2,22.1)$ & $2.9(1.7,4.7)$ \\
$\begin{array}{c}\text { Any alteration of daily activities } \\
\text { (did things differently or had to change } \\
\text { things because of landfill odor) }\end{array}$ & 215 & $9.0(3.5,23.5)$ & $3.2(1.9,5.4)$ \\
\hline
\end{tabular}

${ }^{a}$ Conditional fixed effects logistic regression models adjusted for time of day (morning/evening) of diary record. OR = odds ratio; $\mathrm{CI}=$ confidence interval. 
Table 5

Relation between twice-daily odor reports, mood states, and irritant and physical symptoms.

\begin{tabular}{|c|c|c|}
\hline & $\begin{array}{l}\text { No. of } \\
\text { records }\end{array}$ & $\begin{array}{c}\text { Binary odor } \\
\mathrm{OR}^{a}(95 \% \mathrm{CI})\end{array}$ \\
\hline \multicolumn{3}{|l|}{ Mood states } \\
\hline Stressed & 558 & $2.1(1.2,3.8)$ \\
\hline Angry, grouchy, bad-tempered & 336 & $3.9(1.8,8.5)$ \\
\hline Weary, bushed, exhausted & 469 & $1.8(0.8,4.0)$ \\
\hline Gloomy, blue, unhappy & 358 & $3.1(1.6,6.1)$ \\
\hline Nervous or anxious & 420 & $2.5(1.3,5.0)$ \\
\hline Confused, poor concentration & 262 & $0.3(0.03,2.1)$ \\
\hline Active, energetic, peppy & 415 & $0.6(0.2,1.5)$ \\
\hline \multicolumn{3}{|l|}{ Mucous membrane irritation } \\
\hline Burning eyes & 368 & $5.3(2.5,11.6)$ \\
\hline Burning nose & 386 & $5.0(2.5,10.2)$ \\
\hline Burning throat & 309 & $3.3(1.5,7.1)$ \\
\hline \multicolumn{3}{|l|}{ Upper respiratory } \\
\hline Cough & 334 & $2.0(1.0,3.9)$ \\
\hline Difficulty breathing & 310 & $1.9(0.9,4.2)$ \\
\hline Runny nose & 555 & $2.6(1.4,4.9)$ \\
\hline Sore throat & 359 & $1.9(0.8,4.2)$ \\
\hline \multicolumn{3}{|l|}{ Gastrointestinal } \\
\hline Diarrhea & 164 & $2.6(0.2,29.5)$ \\
\hline Nausea or vomiting & 127 & $2.7(0.5,14.2)$ \\
\hline Loss of appetite & 181 & $0.7(0.2,2.2)$ \\
\hline General ill feeling & 310 & $2.7(1.1,6.6)$ \\
\hline Headache & 387 & $3.3(1.5,7.4)$ \\
\hline Dizzy or lightheaded & 176 & $4.1(1.3,12.5)$ \\
\hline \multicolumn{3}{|l|}{ Skin } \\
\hline Skin rash & 210 & $1.2(0.2,6.3)$ \\
\hline Skin boils & 166 & $4.6(0.6,37.8)$ \\
\hline Itchy skin & 295 & $1.9(0.6,5.6)$ \\
\hline Skin irritation & 187 & $4.7(1.1,21.0)$ \\
\hline Ringing in ears & 176 & $2.9(0.6,14.2)$ \\
\hline
\end{tabular}

${ }^{a}$ Conditional fixed effects logistic regression models adjusted for time of day (morning /evening) of diary record. OR = odds ratio; $\mathrm{CI}=$ confidence interval. 


\section{Table 6}

Relation between twice-daily odor ratings and index variables of negative mood states, and irritant and physical symptoms.

\begin{tabular}{lcc}
\hline & $\begin{array}{c}\text { No. of } \\
\text { records }\end{array}$ & $\begin{array}{c}\text { Binary odor } \\
\left.\mathbf{O R}^{\boldsymbol{a}} \mathbf{( 9 5 \%} \mathbf{C I}\right)\end{array}$ \\
\hline $\begin{array}{c}\text { Any negative mood states } \\
\text { (stressed, angry, weary, gloomy, } \\
\text { nervous, confused) }\end{array}$ & 578 & $5.2(2.8,9.6)$ \\
$\begin{array}{c}\text { Any mucous membrane irritation } \\
\text { (burning eyes, nose, throat) }\end{array}$ & 414 & $3.7(2.0,7.1)$ \\
$\begin{array}{l}\text { Any upper respiratory symptoms } \\
\text { (cough, difficulty breathing, runny } \\
\text { nose, sore throat) }\end{array}$ & 604 & $3.9(2.2,7.0)$ \\
$\begin{array}{l}\text { Any gastrointestinal } \\
\text { (diarrhea, nausea or vomiting, } \\
\text { loss of appetite) }\end{array}$ & 293 & $1.0(0.4,2.6)$ \\
\hline
\end{tabular}

${ }^{a}$ Conditional fixed effects logistic regression models adjusted for time of day (morning /evening) of diary record. $\mathrm{OR}=$ odds ratio; $\mathrm{CI}=$ confidence interval. 